\title{
Lumbar Discectomy: A National Survey of Neurosurgeons and Literature Review
}

\author{
Aleksa Cenic, Edward Kachur
}

\begin{abstract}
Background: To ascertain neurosurgical practices in the surgical management of one-level lumbar discectomies in the Canadian adult population. Methods: One page questionnaire faxed to each Neurosurgeon in Canada with questions relating to their practice in the management of this common neurosurgical procedure. All data analyzed using Chi-square statistics. Results: 112 completed surveys were returned hence, giving a $64 \%$ response rate with the respondents being predominantly adult neurosurgeons. Of the respondents, $88 \%$ perform lumbar discectomy in adults. Only $15 \%$ of respondents had a Spine Fellowship. For preoperative imaging, $44 \%$ use BOTH CT and MRI whereas $28 \%$ use only MRI and 15\% use only CT. Prior to initial skin incision, $57 \%$ use a localization X-ray image. Preoperative antibiotics are prescribed by $92 \%$ of respondents. Majority of respondents (60\%) use a pre-incision local anesthetic, whereas only a minority $(44 \%)$ of respondents employ pre-closure intramuscular injection. With respect to magnification, $70 \%$ use microscope, $19 \%$ loupes, and $8 \%$ neither. Only $12 \%$ use minimally invasive tubular retractors. $68 \%$ remove "as much disc as possible", while $31 \%$ remove "ONLY herniated part". In the case of dural tears, $77 \%$ of respondents use fibrin glue (Tisseel ${ }^{\circledR}$ ). Prior to skin closure, majority of neurosurgeons do NOT use a fat graft (72\%), whereas $61 \%$ of respondents use epidural steroids. With respect to discharge from the hospital, $58 \%$ are discharged on the next day, $18 \%$ on the same day, and $23 \%$ in two days. Return to work is not recommended until at least six weeks post-op (96\%). Most neurosurgeons (93\%) would not operate on an individual with a chief complaint of low back pain. Conclusions: Our survey has identified variations in practice patterns amongst Canadian Neurosurgeons with respect to performing one-level lumbar discectomies. This survey is expected to form a basis for the design of a randomized controlled trial in the evaluation of the best management approach for this common neurosurgical procedure.
\end{abstract}

RÉSUMÉ: Discectomie lombaire : enquête nationale chez les neurochirurgiens et revue de la littérature. Contexte : Le but de l'étude était d'examiner les pratiques chirurgicales concernant la discectomie lombaire à un seul niveau dans la population canadienne adulte. Méthodes : Un questionnaire d'une page, qui portait sur les techniques neurochirurgicales employées, a été envoyé par FAX à tous les neurochirurgiens du Canada. Toutes les données ont été analysées au moyen du test de Chi-carré. Résultats : Cent douze neurochirurgiens, surtout des neurochirurgiens qui traitent des adultes, ont complété et retourné le questionnaire, soit un taux de réponse de $64 \%$. Parmi les répondants, $88 \%$ effectuaient des discectomies chez les adultes. Seulement $15 \%$ des répondants avaient fait une surspécialité dans ce domaine. L'imagerie utilisée avant l'intervention par $44 \%$ des répondants était le CT et l'IRM alors que l'IRM seule était utilisée par $28 \%$ et le CT seul par 15\%. Avant l'incision de la peau, 57\% utilisaient une radiographie de localisation. Quatre-vingt-douze pour cent des répondants prescrivaient une antibiothérapie préopératoire. La majorité des répondants (60) procédaient à une anesthésie locale avant l'incision et seulement une minorité (44) administraient une injection intramusculaire avant la fermeture de la plaie. Soixante-dix pour cent utilisaient un microscope, $19 \%$ utilisaient des loupes et $8 \%$ n'utilisaient aucun instrument de grossissement. Seulement $12 \%$ utilisaient des écarteurs tubulaires d'endoscopie. Soixante-huit pour cent retiraient « le plus de disque possible » alors que $31 \%$ n'enlevaient que «la partie qui faisait hernie». Dans les cas de déchirure de la dure-mère, $77 \%$ des répondants utilisaient une colle à base de fibrine (Tisseel). Avant de fermer la peau, la majorité des neurochirurgiens, soit 72\%, n'utilisaient pas de greffe de graisse et $61 \%$ utilisaient des stéroïdes épiduraux. Cinquante-huit pour cent des patients ont reçu leur congé hospitalier le lendemain, $18 \%$ la journée même et $23 \%$ deux jours plus tard. Le retour au travail n'était pas conseillé avant au moins six semaines (96\%). La plupart des neurochirurgiens (93\%) n'opéreraient pas un patient qui se plaint principalement de douleurs lombaires basses. Conclusions : Notre enquête a identifié des variations dans les pratiques des neurochirurgiens canadiens concernant la discectomie lombaire à un seul niveau. Cette enquête pourra servir de base pour établir le plan d'une étude contrôlée, randomisée, pour déterminer quelle est la meilleure approche thérapeutique dans cette intervention neurochirurgicale fréquente.

Can. J. Neurol. Sci. 2009; 36: 196-200

The prevalence of symptomatic lumbar disc herniation is approximately $2 \%$ in the adult population ${ }^{1}$. When conservative therapy (e.g., analgesia, physiotherapy) does not provide optimum symptom relief, lumbar discectomy is regarded as the treatment of choice with a success rate of 74 to $98 \%{ }^{2}$. However, the adjuvant pre-, intra- and post-operative management principles vary among practising neurosurgeons, such as the use of various diagnostic imaging techniques, epidural steroids, antibiotics, epidural fat grafts, post-operative discharge from hospital, etc.

From the Division of Neurosurgery, McMaster University, Hamilton, Ontario, Canada. Received November 9, 2007. Final Revisions Submitted October 21, 2008. Correspondence to: Edward Kachur, Hamilton General Hospital, 237 Barton Street East, Hamilton, Ontario, L8L 2X2, Canada. 
Given the importance of identifying optimal strategies to manage symptomatic lumbar disc herniations, we conducted a national survey of members of the Canadian Neurosurgical Society to ascertain Neurosurgical practices in the surgical management of one-level lumbar discectomy in the Canadian adult population.

\section{Methods}

A one-page questionnaire was faxed to each Neurosurgeon in Canada. Neurosurgeons were identified through the Canadian Congress of Neurological Surgeons Member Directory and various Neurosurgery Department Websites. After the first set of surveys were faxed, and if no response was obtained by four weeks, a second survey was faxed. For our French counterparts in Quebec, the survey was translated into French. Difference in response rates between Neurosurgeons was evaluated using Chisquare statistics. Statistical significance was taken for a $\mathrm{p}<0.05$. The following questions composed the survey:

- Age (in years)?

- Number of years in practice?

- Do you perform Lumbar Discectomy(s) in your practice?

- Is your practice predominantly: Adult or Peds or Both

- Do you have a Spine Fellowship?

- Preoperative imaging: MRI or CT or BOTH

- Do you use pre-incision localizing plain film X-ray?

- Do you use Preoperative Antibiotics?

- Pre-incision local anaesthetic injection?

- Intramuscular local anaesthetic injection prior to closure?

- Magnification preference? Loupes or Microscope or NONE

- Do you use tubular retractors (e.g., METRx ${ }^{\circledR}$ system, Sofamor-Danek, Memphis, TN, USA)?

- Disc removal preference?

- ONLY herniated part of disc

- As much disc as possible

- For dural tears, do you use Fibrin Glue (Tisseel®, Baxter, Deerfield, IL, USA)?

- Prior to closure, do you use fat graft?

- Do you use epidural steroids prior to closure?

- Discharge from hospital: Same day, Next day, 2 days

- If patient's job requires physical labour, when do you recommend a post-operative return to work (in wks)? $246>6$

- Would you operate on a patient whose MAJOR complaint is back pain?

\section{RESULTS}

In total, 174 faxes were sent out. Giving a $64 \%$ response rate, 112 were returned. The predominant Neurosurgical practise was as follows: Adult 95, Pediatric 10 and Combined 3. Hence, 98 surveys were used for analysis of the management of One-Level Lumbar Disc Herniation. Of respondents who treat adults, $88 \%$ perform Lumbar Discectomies. The mean age of respondents was 48.1 years (range 32-69 years). A Spine Fellowship was completed by $15.1 \%$ of the respondents.

\section{Imaging}

With respect to acquiring a radiological diagnosis of lumbar disc herniation, $44 \%$ of surgeons use both MRI and CT preoperatively, whereas $28 \%$ use only MRI and $15 \%$ use only
CT. Either CT or MRI is used by $13 \%$ of the respondents. Intraoperatively, majority of respondents (57\%) use a preincision localization plain film $\mathrm{x}$-ray $(\mathrm{p}=0.1)$.

\section{Use of Intraoperative Local Anesthetic}

Majority of respondents $(60 \% ; \mathrm{p}<0.05)$ use a pre-incision local anesthetic, whereas no agreement for pre-closure intramuscular injection was obtained (44\% yes vs. $56 \%$ no; $\mathrm{p}=0.2)$.

\section{Peri-Operative Antibiotics}

As a mainstay of their practice, $92 \%$ of the neurosurgeons use prophylactic preoperative antibiotics $(\mathrm{p}<0.05)$.

\section{Epidural Fat and Steroids}

Most surgeons do not place epidural fat grafts over the exposed nerve root prior to skin closure (72\% versus $27 \%$; $\mathrm{p}<0.05)$. One surgeon responded with "depends/sometimes" $(1 \%)$.

With respect to the use of epidural steroids prior to closure, $61 \%$ of the respondents implement this practice $(\mathrm{p}<0.05)$; whereas, $2 \%$ responded with "depends/sometimes".

\section{Technical Aspects}

With respect to intraoperative magnification, $70 \%$ use microscope, $19 \%$ loupes, $3 \%$ both, and $8 \%$ neither. Only $12 \%$ of respondents use minimally invasive tubular retractor systems (e.g., METRx®). Majority of surgeons (68\%) remove "as much disc as possible", while only $31 \%$ remove "only herniated part" $(\mathrm{p}<0.05)$. In the case of iatrogenic dural tears, $77 \%$ of respondents use fibrin glue (Tisseel@) to cover the tear.

\section{Contraindications for Surgery}

In an individual with a major complaint of low back pain rather than radicular leg pain, 93\% of neurosurgeons would not operate on a herniated lumbar disc.

\section{Discharge Home and Return-to-Work}

Figure 1 shows the response rate for the time to discharge from hospital post-surgery. From the $18 \%$ of respondents who discharge patients home the "same day", 72\% use both preincision skin and pre-closure intramuscular injection of local anaesthetic, but only $33 \%$ use minimally invasive tubular retractors.

\section{Discussion}

Our survey shows that the majority of neurosurgeons performing lumbar discectomies prescribe prophylactic preoperative antibiotics. Such practice is supported by a metaanalysis that demonstrated a benefit for prophylactic antibiotics in reducing post-operative infections in spinal surgery ${ }^{3}$. Also, in a large retrospective review of 1030 lumbar discectomy procedures, Schnoring et al showed a statistically significant lower post-operative infection rate of $0.2 \%$ with a single dose preoperative antibiotic versus $2.8 \%$ without $^{4}$.

The majority of respondents use a pre-incision local anaesthetic injection. Such practice has been shown to 


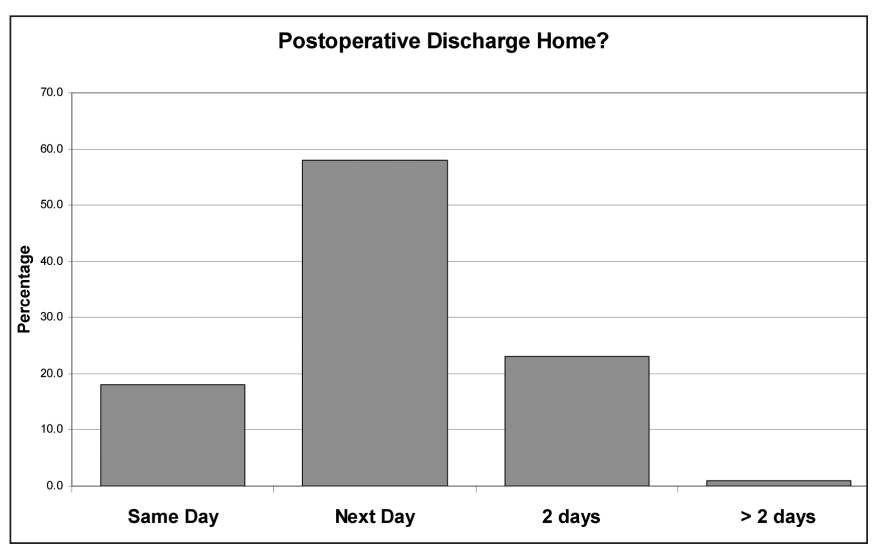

Figure 1: Post-operative Length of Stay in Hospital. Statistically significant differences for "next day" versus "same day" and "2 days" $(p<0.05)$.

significantly reduce postoperative lumbar pain ${ }^{5,6}$. With respect to infiltration of the paraspinal muscles with local anesthetic prior to skin closure, there appears to be no agreement amongst Canadian neurosurgeons. This response is contrary to the findings of multiple randomized controlled trials that have consistently revealed less use of analgesic medications postoperatively when local anesthetic (e.g., bupivicaine) was infiltrated into the wound prior to skin closure in lumbar discectomies $^{6-8}$.

The trend in our survey was for neurosurgeons to remove "as much disc as possible" compared to only removing the herniated disc portion when performing a lumbar discectomy. By this question we wanted to find out whether neurosurgeons tend to only remove the compression on the nerve root / thecal sac from a sequestrated disc or subligamentous herniation or continue to remove disc material from the disc space after removing the compressive material in order to possibly prevent a re-herniation. As shown by Thome et $\mathrm{al}^{9}$ in a prospective randomized controlled trial comparing lumbar sequestrectomy versus microdiscectomy, there is a trend in favor of sequestrectomy with respect to post-operative clinical outcomes (e.g., reduced back pain and radiculopathy) and less reherniation rates. Although a recent prospective observational study by Carragee et $\mathrm{al}^{10}$ showed a trend for increased disc reherniation when sequestrectomy is performed compared to aggressive removal of intervertebral disc, overall clinical outcomes were less satisfactory in the aggressive disc removal group.

Although recent studies ${ }^{11-13}$ have shown a shorter hospital stay, less narcotic use post-operatively, and better wound cosmesis with the use of minimally invasive tubular retractors, only a small number of neurosurgeons (12\%) use tubular retractors for lumbar discectomy in Canada. With the recent trend toward minimally invasive spine surgery in North America, the use of tubular retractors may grow in the future.

Epidural free fat grafts are used with the intention to prevent epidural fibrosis over the nerve root hence, reduce the rate of recurrent radicular symptoms postoperatively. From our survey,

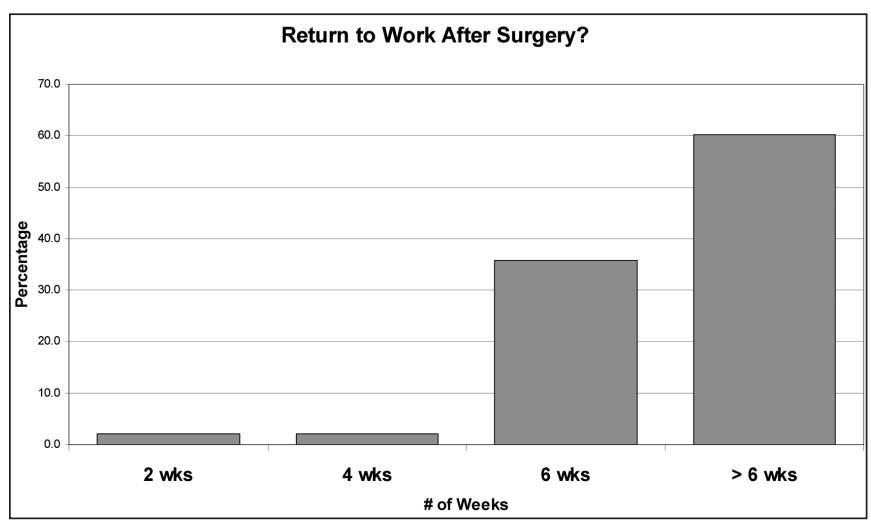

Figure 2: Post-operative Return to Work. Statistically significant differences for "6 weeks" versus "> 6 weeks" $(p<0.05)$.

less than $30 \%$ of respondents use epidural free fat grafts. This response is in keeping with three prospective randomized controlled studies that showed no benefit in clinical outcomes when epidural fat grafts were used ${ }^{14-16}$. Moreover, in a case report of three symptomatic patients, Martin-Ferrer had shown that autologous fat grafts which were removed post-operatively showed a fibrotic infiltration and associated hypertrophic epidural scarring ${ }^{17}$.

During lumbar discectomy, epidural corticosteroids have been used by some surgeons to decrease pain following surgery. In this study, majority of neurosurgeons $(61 \%)$ do not use epidural corticosteroids prior to closure of the incision. In a randomized controlled study of 84 patients undergoing microdiscectomy, Lavyne et al showed no difference in postoperative clinical and functional outcomes and postoperative consumption of analgesic medications between the corticosteroid and control groups ${ }^{18}$. Although a more recent randomized controlled trial of 61 patients undergoing lumbar discectomy demonstrated a decrease in postoperative low back pain for the first 14 days in the corticosteroid group compared to the control group, radicular leg pain was not different between groups ${ }^{19}$. Moreover, with the use of epidural steroids, one must consider the possibility of postoperative epidural abscess formation. In a retrospective review of 31 patients receiving epidural methylprednisolone during lumbar discectomy, Lowell et al found an approximate $10 \%$ epidural abscess rate postoperatively ${ }^{20}$.

The post-operative length of hospital-stay varied among neurosurgeons. Most patients $(>50 \%)$ are sent home the next day. Less than $20 \%$ of patients are sent home the day of surgery. Discharge of patients from hospital post-operatively may be influenced by many factors such as the patients' comorbidities, or poor control of post-operative pain. As shown in our survey, majority of neurosurgeons who discharge their patients home the "same day" use pre-skin incision and pre-wound closure intramuscular injection of local anaesthetic to decrease postoperative pain. At our centre, there's a trend to discharge patients 
home the evening of surgery if the discectomy was done in the morning with appropriate analgesia prescription.

Over $90 \%$ of respondents recommend that the patient does not return to work until at least six weeks post-surgery if patient employment requires physical labour. Such recommendations may be altered depending on the physical nature of the patient's work (e.g., sedentary work versus physical labour).

In Canada, $93 \%$ of neurosurgeons would not perform surgery for a major complaint of low back pain. This practice is contrary to the findings of The Maine Lumbar Spine Study ${ }^{21}$ which looked at ten year outcomes of patients with sciatica due to a lumbar disc herniation. This study showed that patients' with predominantly low back pain improved significantly by $69 \%$ after surgery. Furthermore, as shown by Thome et $\mathrm{al}^{9}$, lumbar discectomy improves both sciatica and low back pain by at least $80 \%$. Hence, the traditional perspective amongst neurosurgeons that lumbar discectomy is only effective for radicular leg symptoms and not low back pain may need to be re-addressed and further investigated in the future.

Although there's a trend in our survey (57\%) for the use of pre-incision localization X-ray, no statistically significant agreement was reached. The advantage of using this intraoperative imaging method is to increase the accuracy of the chosen lumbar level hence, a smaller skin incision. The disadvantages are the inherent X-ray dose, slight increase in surgical operating time and use of hospital resources.

Over $40 \%$ of surgeons use both MRI and CT for the diagnosis of lumbar disc herniation. However, given an option, surgeons tend to chose MRI as the diagnostic imaging of choice over CT ( $28 \%$ versus $15 \%$ respectively). This is in agreement with multiple comparison studies in the literature showing MRI to have superior sensitivity and specificity in diagnosing lumbar disc herniations compared to CT, especially in cases of intradural herniations ${ }^{22-24}$. Moreover, the morphometric features of the disc herniation are readily visible with MRI with the advantage of having no radiation exposure.

Incidental dural tears, although not a common intraoperative complication during lumbar discectomy, have been reported as high as $3 \%$ in some large case series ${ }^{25,26}$. With respect to intraoperative dural tears, fibrin glue (Tisseel ${ }^{\circledR}$ ) is used by over $75 \%$ of Canadian neurosurgeons. Although primary repair of the dural tear using sutures is the mainstay of treatment, due to the adhesive and sealant properties of fibrin glue, it may further assist in preventing a CSF leak and augment the water-tight closure $^{27}$.

As with any such survey investigating the practice patterns for a common neurosurgical problem, one must consider the effect of non-responder bias. It may be possible that nonrespondents have different treatment strategies than those who did respond. However, we feel that our relatively high response rate $(64 \%)$ may have limited this effect. Although it is estimated that there are approximately 180 neurosurgeons in Canada, we non-selectively only sent out our survey to 174 . Our number comprised most practicing neurosurgeons (i.e., not retired and affiliated with a tertiary or secondary neurosurgical care institution) in Canada; hence, our survey may not be generalizable to other settings and populations.

Finally, we attempted to be as clear as possible with the questions in our survey. We acknowledge that our questions may have been interpreted in different ways, based on the wording.
We attempted to be as non-biased as possible in presenting the results.

From our survey, $88 \%$ of Canadian adult neurosurgeons perform lumbar discectomies. Majority of surgeons utilize preoperative antibiotics, and do not use epidural free fat grafts or corticosteroids prior to completion of the operative procedure. With respect to iatrogenic dural tears, most surgeons use Tisseel ${ }^{\circledR}$ to prevent postoperative CSF leaks. Although no consensus was reached with respect to the use of intramuscular local anesthetic injection upon completion of the operation, preincisional subcutaneous anesthetic is employed widely. Most patients are discharged home from hospital on post-operative day one, and are allowed to return to a physical labour job after a minimum of six weeks from day of surgery. In cases where low back pain predominates over radicular leg pain, most surgeons would not recommend surgical intervention in those patients with lumbar disc herniation.

Our survey has identified variations in practice patterns amongst Canadian Neurosurgeons with respect to performing one-level lumbar discectomy. This survey is expected to form a basis for the design of a randomized controlled trial in the evaluation of the best management approach for this common procedure.

\section{ACKNOWLEDGEMENTS}

The authors thank Miss Christina Vandervlist for assistance with the faxing of the surveys.

\section{REFERENCES}

1. Hanley E. Surgical indications and techniques. The International Society for the Study of the Lumbar Spine. The lumbar spine, 2nd ed. Philadelphia: WB Saunders; 1996. p. 492-524.

2. Frizzell RT, Hadley MN. Lumbar microdiscectomy with medial facetectomy. Techniques and analysis of results. Neurosurg Clin N Am. 1993 Jan;4(1):109-15.

3. Barker FG. Efficacy of prophylactic antibiotic therapy in spinal surgery: a meta-analysis. Neurosurgery. 2002 Aug;51(2): 391-400.

4. Schnoring M, Brock M. Prophylactic antibiotics in lumbar disc surgery: analysis of 1,030 procedures. Zentralbl Neurochir. 2003;64(1):24-9.

5. Mullen JB, Cook WA. Reduction of postoperative lumbar hemilaminectomy pain with Marcaine. Technical note. J Neurosurg. 1979 Jul;51(1):126-7.

6. Ersayli DT, Gurbet A, Bekar A, Uckunkaya N, Bilgin H. Effects of perioperatively administered bupivacaine and bupivacainemethylprednisolone on pain after lumbar discectomy. Spine. 2006 Sep 1;31(19):2221-6.

7. Hernandez-Palazon J, Tortosa Serrano JA, Burguillos Lopez S, Molero Molero E. Infiltration of the surgical wound with local anesthetic for postoperative analgesia in patients operated on for lumbar disc herniation. Comparative study of ropivacaine and bupivacaine. Rev Esp Anestesiol Reanim. 2001 Jan;48(1):17-20.

8. Milligan KR, Macafee AL, Fogarty DJ, Wallace RG, Ramsey P. Intraoperative bupivacaine diminishes pain after lumbar discectomy. A randomized double-blind study. J Bone Joint Surg Br. 1993 Sep;75(5):769-71.

9. Thome C, Barth M, Scharf J, Schmiedek P. Outcome after lumbar sequestrectomy compared with microdiscectomy: a prospective randomized study. J Neurosurg Spine. 2005 Mar;2(3):271-8.

10. Carragee EJ, Spinnickie AO, Alamin TF, Paragioudakis S. A prospective controlled study of limited versus subtotal posterior discectomy: short-term outcomes in patients with herniated lumbar intervertebral discs and large posterior anular defect. Spine. 2006 Mar 15;31(6):653-7. 
11. Schizas C, Tsiridis E, Saksena J. Microendoscopic discectomy compared with standard microsurgical discectomy for treatment of uncontained or large contained disc herniations. Neurosurgery. 2005 Oct;57(4 Suppl):357-60; discussion 357-60.

12. Wu X, Zhuang S, Mao Z, Chen H. Microendoscopic discectomy for lumbar disc herniation: surgical technique and outcome in 873 consecutive cases. Spine. 2006 Nov 1;31(23):2689-94.

13. Perez-Cruet MJ, Foley KT, Isaacs RE, Rice-Wyllie L, Wellington R, Smith MM, et al. Microendoscopic lumbar discectomy: technical note. Neurosurgery. 2002 Nov;51(5 Suppl):S129-36.

14. Jensen TT, Asmussen K, Berg-Hansen EM, Lauritsen B, Manniche C, Vinterberg $\mathrm{H}$, et al. First-time operation for lumbar disc herniation with or without free fat transplantation. Prospective triple-blind randomized study with reference to clinical factors and enhanced computed tomographic scan 1 year after operation. Spine. 1996 May 1;21(9):1072-6.

15. Gorgulu A, Simsek O, Cobanoglu S, Imer M, Parsak T. The effect of epidural free fat graft on the outcome of lumbar disc surgery. Neurosurg. Rev. 2004 Jul;27(3):181-4.

16. Bernsmann K, Kramer J, Ziozios I, Wehmeier J, Wiese M. Lumbar micro disc surgery with and without autologous fat graft. A prospective randomized trial evaluated with reference to clinical and social factors. Arch Orthop Trauma Surg. 2001 Sep;121(8): 476-80.

17. Martin-Ferrer S. Failure of autologous fat grafts to prevent postoperative epidural fibrosis in surgery of the lumbar spine. Neurosurgery. 1989 May;24(5):718-21.

18. Lavyne MH, Bilsky MH. Epidural steroids, postoperative morbidity, and recovery in patients undergoing microsurgical lumbar discectomy. J Neurosurg. 1992 Jul;77(1):90-5.

19. Debi R, Halperin N, Mirovsky Y. Local application of steroids following lumbar discectomy. J Spinal Disord Tech. 2002 Aug;15(4):273-6.
20. Lowell TD, Errico TJ, Eskenazi MS. Use of epidural steroids after discectomy may predispose to infection. Spine. 2000 Feb 15; 25(4):516-9.

21. Atlas SJ, Keller RB, Wu YA, Deyo RA, Singer DE. Long-term outcomes of surgical and nonsurgical management of sciatica secondary to a lumbar disc herniation: 10 year results from the Maine lumbar spine study. Spine. 2005 Apr 15;30(8):927-35.

22. Pevsner PH, Ondra S, Radcliff W, George E, McDonnell D, Furlow $\mathrm{T}$, et al. Magnetic resonance imaging of the lumbar spine. A comparison with computed tomography and myelography. Acta Radiol Suppl. 1986;369:706-7.

23. Jackson RP, Cain JE, Jacobs RR, Cooper BR, McManus GE. The neuroradiographic diagnosis of lumbar herniated nucleus pulposus: II. A comparison of computed tomography (CT), myelography, CT-myelography, and magnetic resonance imaging. Spine. 1989 Dec;14(12):1362-7.

24. D'Andrea G, Trillo G, Roperto R, Celli P, Orlando ER, Ferrante L. Intradural lumbar disc herniations: the role of MRI in preoperative diagnosis and review of the literature. Neurosurg Rev. 2004 Apr;27(2):75-80; discussion 81-2. Epub 2003 Oct 15.

25. Tafazal SI, Sell PJ. Incidental durotomy in lumbar spine surgery: incidence and management. Eur Spine J. 2005 Apr;14(3): 287-90.

26. McCulloch JA. Complications in lumbar microsurgery. In: Wiliams RW, McCulloch JA, Young PH, editors. Microsurgery of the lumbar spine. Rockville, MD: Aspen; 1990. p. 159-66.

27. Bosacco SJ, Gardner MJ, Guille JT. Evaluation and treatment of dural tears in lumbar spine surgery: a review. Clin Orthop Relat Res. 2001 Aug;(389):238-47. 